\title{
Changes in Ventricular Refractoriness and Conduction Velocity Induced by Local Hypothermia and Hyperthermia
}

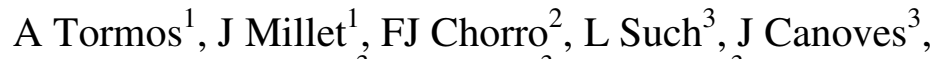 \\ L Mainar $^{3}$, E Blasco $^{3}$, I Trapero ${ }^{3}$ \\ ${ }^{1}$ Grupo BET, Universidad Politécnica de Valencia, Spain \\ ${ }^{2}$ Servicio de Cardiología, Hospital Clínico Universitario de Valencia, Spain \\ ${ }^{3}$ Laboratorio de Fisiología, Universidad de Valencia, Spain
}

\begin{abstract}
VF pattern is related to the electrophysiological parameters of the myocardium. Although the influence of global temperature on these parameters is known, the effects of its regional variations have not been sufficiently studied. We examined the effects of local hypothermia and hyperthermia on refractoriness and conduction velocity (VC), during constant pacing at cycle lengths of $250 \mathrm{~ms}$. In an experimental model (rabbit isolated heart) we used a new method to perform epicardial cooling and heating on the registered surface.

The results show that local variations of temperature generate heterogeneity in the electrophysiological properties of the heart. Hypothermia prolongs refractoriness and decreases $V C$, in a reversible manner. Hyperthermia $\left(42{ }^{\circ} \mathrm{C}\right)$ has the opposite effects. The wavelength of the cardiac impulse is not altered because of the opposite and proportional actions on functional refractory period and $V C$.
\end{abstract}

\section{Introduction}

Temperature influences the electrophysiological properties of cardiac cells [1,2]. Hypothermia increases the duration of the ventricular action potentials and prolongs the ventricular effective refractory period [1-4]. Myocardial cooling depolarizes the resting membrane potential and decreases the maximum rate of phase 0 of the action potential, the conduction velocity, the peak potentials reached during depolarization, and the delayed rectifier and inwardly rectifying potassium currents $[5,6]$. Hypothermia has been associated to an increased susceptibility for ventricular arrhythmias and ventricular fibrillation (VF), and this effect has been related to slowing of conduction, a heterogeneous increase in ventricular repolarization, and the dispersion of refractoriness [4,7]. On the other hand, myocardial warming shortens the APD and increases conduction velocity. Temperature variations may cause important differences in excitation patterns with regard to normothermic conditions (basal temperature, $37^{\circ} \mathrm{C}$ ), not only under normal operation but also during arrhythmia. Some experimental works, using isolated heart preparations, have related the myocardial electrophysiological parameters with the fibrillatory pattern, specifically with the activation frequency of $\mathrm{VF}$ $[8,9]$. In most cases, the temperature modifications used have been global.

Although information is available on the electrophysiological effects of temperature, no systematic studies have been made, in an experimental model, of the way in which local hypothermia and local hyperthermia affects electrophysiological parameters of the myocardium.

\section{Methods}

To perform, in a controlled manner, local temperature modifications in perfused hearts (above and below the basal values) a customized device was used. This device, developed by our grup in a recent investigation, is capable of cooling or heating just the epicardial surface that is being analyzed [10]. It basically consists of an extraflat multiple-electrode on thick-film technology, joined at a thermoelectric cooler. Its main features are: 36 unipolar silver/silver chloride electrodes, electrode diameter $0.3 \mathrm{~mm}$, inter-electrode distance $1.5 \mathrm{~mm}$. A conventional plaque with stainless steel electrodes (121 unipolar electrodes, electrode diameter $0.125 \mathrm{~mm}$, interelectrode distance $1 \mathrm{~mm}$ ) was also employed.

These electrodes were used to record epicardial signals during constant stimulation in 18 experimental models (New Zeland rabbits, mean weight $3.1 \pm 1.1 \mathrm{~kg}$ ).

\subsection{Experimental preparation}

All experiments complied with the "European Convention for the Protection of Vertebrate Animals used for Experimental and other Scientific Purposes" (Strasbourg, 18.III.1986). 


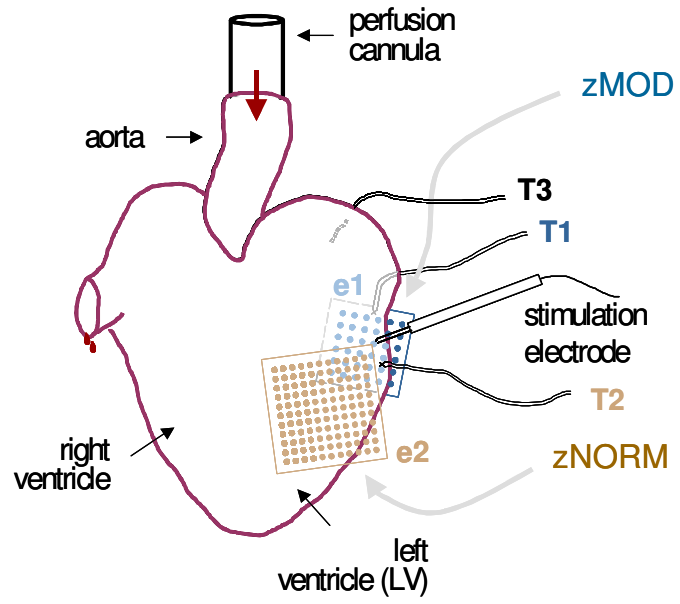

Figure 1. Location of the electrodes. Electrode for thermal modifications (e1) and conventional electrode (e2). Thermocouples at modified zone (T1), normothermic zone (T2) and inside left ventricle (T3).

After anesthesia with ketamine and heparinization, the hearts (mean weight $10.3 \pm 2.7 \mathrm{~g}$ ) were removed and immersed in cold Tyrode solution $\left(4^{\circ} \mathrm{C}\right)$. After isolation, the aorta was connected to a Langendorff system for perfusion of Tyrode solution at constant pressure (60 $\left.\mathrm{mmHg}, 37 \pm 0.5^{\circ} \mathrm{C}\right)$. The composition of the perfusion fluid was $(\mathrm{mM}) 130 \mathrm{NaCl}, 24.2 \mathrm{NaHCO}_{3}, 4.7 \mathrm{KCl}, 2.2$ $\mathrm{CaCl}_{2}, 1.2 \mathrm{NaH}_{2} \mathrm{PO}_{4}, \quad 0.6 \mathrm{MgCl}_{2}$, and 12 glucose. Oxygenation was carried out with a mixture of $95 \% \mathrm{O}_{2}$ and $5 \% \quad \mathrm{CO}_{2}$. Figure 1 shows the location of the electrodes in the isolated heart. The custom device was positioned at the posterior wall of the left ventricle (modified zone, zMOD) and the conventional one was positioned at the epicardial surface of the anterior wall of the same ventricle (normothermic zone, zNORM). The indifferent electrode consisted on a $4 \times 6 \mathrm{~mm}$ silver plaque located over the cannulated aorta. Pacing (2 ms rectangular pulses, intensity twice the diastolic threshold) was carried out with a GRASS ${ }^{\circledR}$ S88 stimulator with a stimulus isolation unit (SIU5).The cardiac mapping system MAPTECH was used to acquire the electrical activity of the epicardium. The electrograms were amplified with a gain of 50-300, broadband (1-400 Hz) filtered, multiplexed and recorded. The sampling rate for each channel was $1 \mathrm{kHz}$. The endocardial and epicardial (zMOD and zNORM) temperatures were measured with miniaturized thermocouples and registered with a digital Fluke ${ }^{\circledR}$ thermometer.

The schematic drawing in Figure 2 shows the experimental preparation with the isolated heart and each part that forms the system in the experiments.

\subsection{Protocol and data analysis}

In order to quantify local ventricular refractoriness, we applied the extrastimulus test. The functional refractory period (PRF) was obtained from the minimum interval between activations. The effective refractory period (PRE) was obtained from the longest interval between the last stimulus of the train and the extrastimulus, with the condition that the last no resulted in ventricular capture. On the other hand, VC was estimated by dividing the distance between two nearby electrodes located in the direction of the wavefront, by the delay between their respective depolarizations. For this purpose, activation

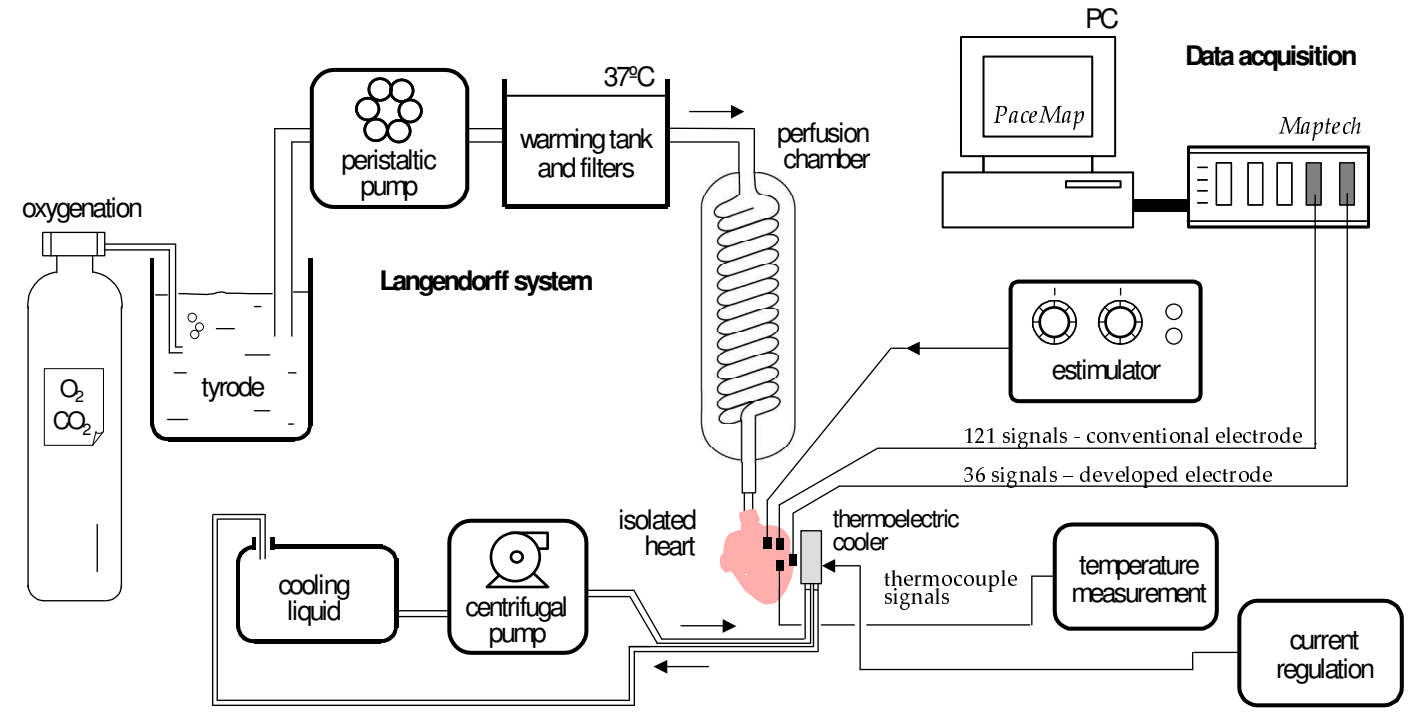

Figure 2. Experimental preparation and equipments. Bottom: developed system for temperature modification and signal recording. 
maps were obtained in each phase of the protocol. In order to obtain them, we previously determined the local activation periods by marking the moments of maximum negative slope in the electrograms. The wavelength of the ventricular activation process (LO) was calculated as the product of the PRF and VC. In order to acquire the signals and obtain the parameters, we used CardioMapping and PaceMap software, running under MAPTECH system.

Twenty minutes after the electrodes were positioned, the extrastimulus test with one extrastimulus was applied at basal temperature $\left(37^{\circ} \mathrm{C}\right)$. The basic cycle was fixed at $250 \mathrm{~ms}$. The extrastimulus was reduced in steps of 10 $\mathrm{ms}$ from $200 \mathrm{~ms}$ to reach the PRF. Activation maps were obtained from the last interval of the basic cycle. The test was repeated five minutes after the epicardial temperature reached its minimum value $\left(17^{\circ} \mathrm{C}\right.$ in most experiments) and after temperature was again normalized. This was achieved by adjusting the current of the thermoelectric cooler properly. In other phase of the experiment, the process was repeated at $37^{\circ} \mathrm{C}$ and $42^{\circ} \mathrm{C}$.

Data are presented as mean values \pm standard deviation. Comparisons between two sets of data were made with Student's t-test for paired data. Differences were considered significant at $p<0.05$, otherwise non significant (ns).

\section{Results}

In zMOD, during hypothermia, PRE and PRF were higher than at $37{ }^{\circ} \mathrm{C},(146 \pm 15 \mathrm{~ms}$ and $168 \pm 17 \mathrm{~ms}$ vs. $124 \pm 9 \mathrm{~ms}$ and $139 \pm 12 \mathrm{~ms}, \mathrm{p}<0.001)$. In this zone, cooling resulted in a VC slowing $(46 \pm 7 \mathrm{~cm} / \mathrm{s}$ vs. $63 \pm 9 \mathrm{~cm} / \mathrm{s}$, $\mathrm{p}<0.005)$. Moreover, local hyperthermia shortened the refractory periods vs. the directly preceding control value $(\mathrm{PRE}=96 \pm 13 \mathrm{~ms}$ and $\mathrm{PRF}=109 \pm 8 \mathrm{~ms}, \mathrm{p}<0.001) . \mathrm{VC}$ was higher at $42{ }^{\circ} \mathrm{C}$ than at $37{ }^{\circ} \mathrm{C}(69 \pm 18 \mathrm{~cm} / \mathrm{s}$ vs. $61 \pm 16$ $\mathrm{cm} / \mathrm{s}, \mathrm{p}<0.05)$. The effects of heating and cooling remitted after temperature returned to control value. Temperature of the region covered by the conventional electrode (zNORM) presented no changes; idem with endocavitary temperature of left ventricle. However, a small but significant variation in refractoriness was also found in zNORM during cooling zMOD (PRF $=142 \pm 12 \mathrm{~ms}$ vs. $136 \pm 12 \mathrm{~ms}, \mathrm{p}<0.05)$, not during heating $(\mathrm{PRF}=123 \pm 14$ $\mathrm{ms}$ vs. $125 \pm 8 \mathrm{~ms}$, ns). In this zone, VC showed no variations during hypothermia $(66 \pm 16 \mathrm{~cm} / \mathrm{s}$ vs. $66 \pm 15$ $\mathrm{cm} / \mathrm{s}$, ns $)$ or hyperthermia $(65 \pm 16 \mathrm{~cm} / \mathrm{s}$ vs. $68 \pm 22 \mathrm{~cm} / \mathrm{s}$, $\mathrm{ns})$. The results for numerical data are shown as bar diagrams in Figure 3 and Figure 4 . Regarding wavelength, there were some differences in the mean value during hypothermia in zMOD $\left(7.7 \pm 1.1 \mathrm{~cm}\right.$ at $17^{\circ} \mathrm{C}$, vs. $8.8 \pm 1.8 \mathrm{~cm}$ at $37^{\circ} \mathrm{C}$ ) and hyperthermia $(7.3 \pm 2.3 \mathrm{~cm}$ at $42{ }^{\circ} \mathrm{C}$, vs. $7.6 \pm 2.3 \mathrm{~cm}$ at $37^{\circ} \mathrm{C}$ ), but in any case none of them were statistically significant. In zNORM, LO did
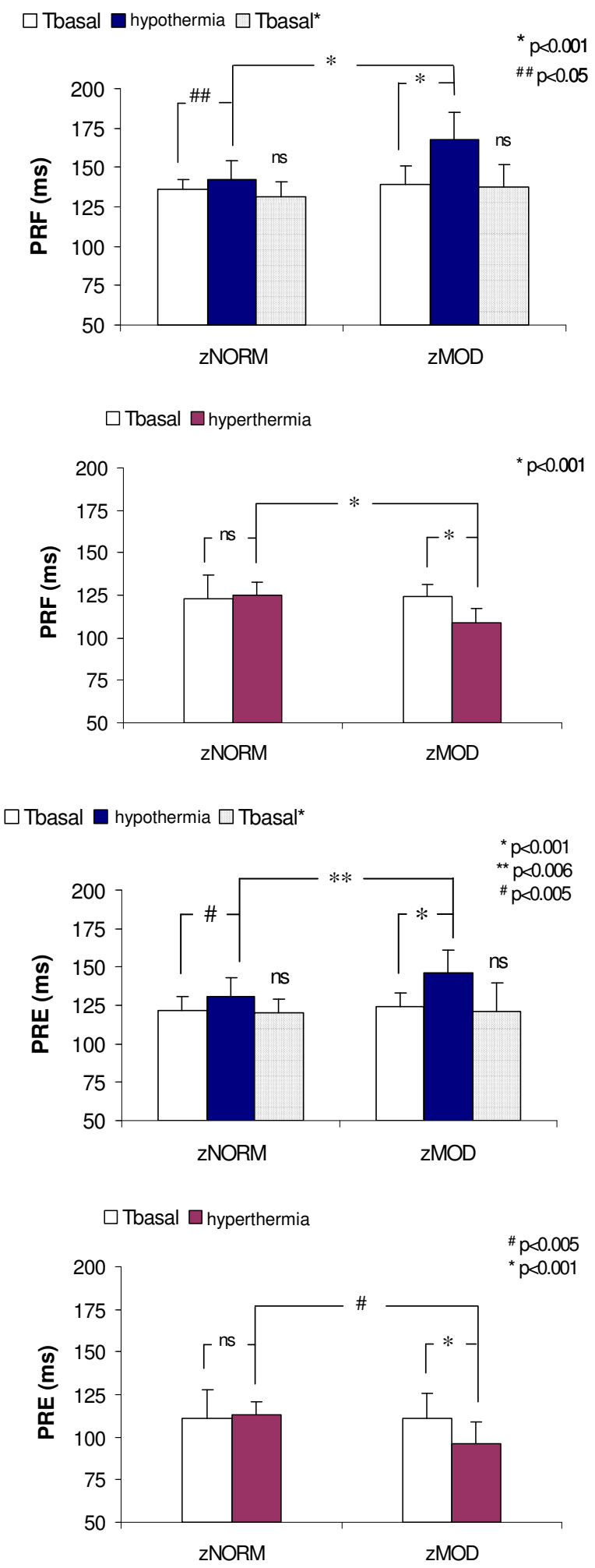

Figure 3. Functional (PRF) and effective (PRE) refractory periods. Variations during hypothermia and hyperthermia Tbasal*: back to $37^{\circ} \mathrm{C}$ from hypothermia. 

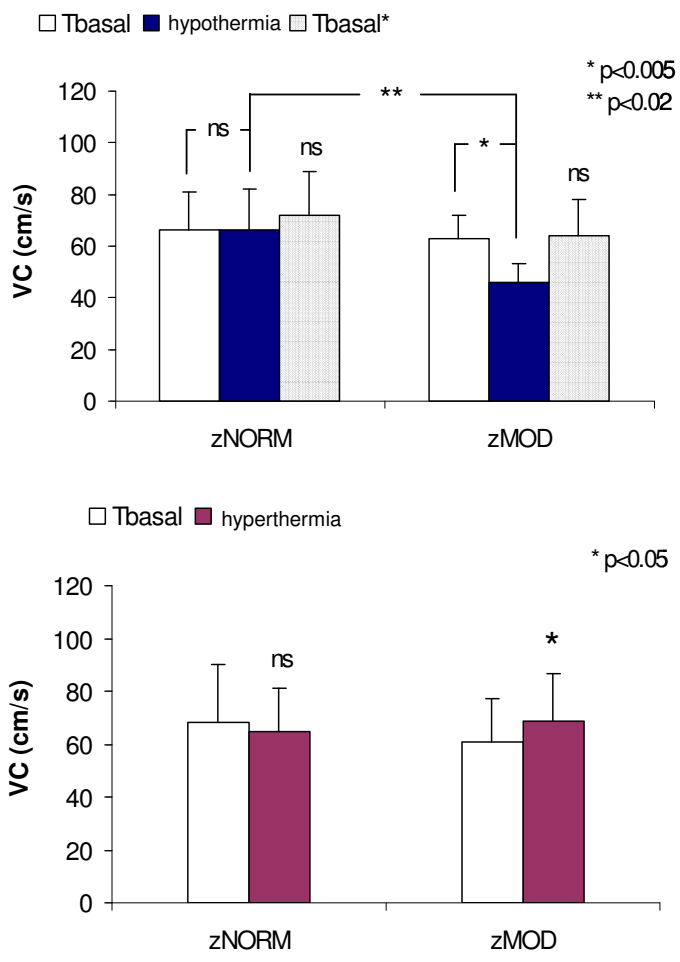

Figure 4. Conduction velocity. Variations during hypothermia (top) and hyperthermia (bottom). Tbasal*: back to $37^{\circ} \mathrm{C}$ from hypothermia.

not show significant changes either, both during hypothermia $\left(9.4 \pm 2.6 \mathrm{~cm}\right.$ at $17^{\circ} \mathrm{C}$, vs. $9.0 \pm 2.0 \mathrm{~cm}$ at 37 $\left.{ }^{\circ} \mathrm{C}\right)$ or hyperthermia $\left(7.6 \pm 2.1 \mathrm{~cm}\right.$ at $42{ }^{\circ} \mathrm{C}$, vs. $8.2 \pm 2.0 \mathrm{~cm}$ at $37^{\circ} \mathrm{C}$ ).

\section{Discussion and conclusions}

The device developed allows us to modify the myocardial temperature locally. Epicardial temperature can be set to the required value and stabilized during the protocol. In our model, the results show that local modifications of temperature have a modulation effect on the electrophysiology of the heart. This model can be useful, for example, to simulate pathological conditions that facilitate the generation of arrhythmias.

Local cooling or heating generates heterogeneity in the electrophysiological parameters of the myocardium. The minor changes experienced by the PRE and PRF outside the modified zone could be caused by a partial transmission of the local temperature. We must bear in mind that temperatures were registered in just one point of each zone. Local hypothermia $\left(17^{\circ} \mathrm{C}\right)$ prolongs refractoriness and decreases conduction velocity, in a reversible manner. Hyperthermia $\left(42^{\circ} \mathrm{C}\right)$ has the opposite effects. The wavelength of the cardiac impulse has been related to the facilitation of reentrant arrhythmias, and is well known that of both hypothermia and hyperthermia have proarrhythmic effects. In our model, this parameter was not altered, probably due to the opposite and proportional actions on refractoriness and $\mathrm{VC}$.

\section{Acknowledgements}

This work was partly supported by FIS research grant PI020594.

\section{References}

[1] Herve JC, Yamaoka K, Twist VW, Powell T, Ellory JC, Wang LC. Temperature dependence of electrophysiological properties of guinea pig and ground squirrel myocytes. Am J Physiol.1992 Jul; 263(1):R177-84.

[2] Sprung J, Laszlo A, Turner LA, Kampine JP, Bosnjak ZJ. Effects of hypothermia, potassium and verapamil on the action potential characteristics of canine cardiac Purkinje fibers. Anesthesiology. 1995 Mar; 82(3):713-22.

[3] Tachibana H, Kubota I, Yamaki M, Watanabe T, Tomoike H. Canine model of ventricular fibrillation using programmed stimuli and localized myocardial warming or cooling. Jpn Heart J. 1999 Mar; 40(2):179-88.

[4] Ujhelyi MR, Sims JJ, Dubin SA, Vender J, Miller AW. Defibrillation energy requirements and electrical heterogeneity during total body hypothermia. Crit Care Med. 2001 May; 29(5):1006-11.

[5] Kiyosue T, Arita M, Muramatsu H, Spindler AJ, Noble D. Ionic mechanisms of action potential prolongation at low temperature in guinea-pig ventricular myocytes. J Physiol. 1993 Aug; 468:85-106.

[6] Spear JF, Moore EN. Modulation of quinidine-induced arrhythmias by temperature in perfused rabbit heart. Am J Physiol Heart Circ Physiol. 1998 Mar; 274(3):H817-28.

[7] Mortensen E, Berntsen R, Tveita T, Lathrop DA, Refsum H. Changes in ventricular fibrillation threshold during acute hypothermia. A model for future studies. J Basic Clin Physiol Pharmacol. 1993 Oct-Dec; 4(4):313-9.

[8] Chorro FJ, Guerrero J, Ferrero A, Tormos A, Mainar L, Millet J, Canoves J, Porres JC, Sanchis J, Lopez-Merino V, Such L. Effects of acute reduction of temperature on ventricular fibrillation activation patterns. Am J Physiol Heart Circ Physiol. 2002 Dec; 283(6):H2331-40.

[9] Chorro FJ, Canoves J, Guerrero J, Mainar L, Sanchis J, Such L, Lopez-Merino V. Alteration of ventricular fibrillation by flecainide, verapamil, and sotalol: an experimental study. Circulation. 2000 Apr 4; 101(13):1606-15.

[10] Tormos A, Millet J, Chorro FJ, Such L. Modifications in the Activation Process during Ventricular Fibrillation by Local Hyperthermia. Computers in Cardiology 2004;31:25-28.

Address for correspondence.

Alvaro Tormos.

Departamento de Ingeniería Electrónica.

Universidad Politécnica de Valencia.

Camino de Vera 14 - 46022 SPAIN. 